\title{
BELANGRIKE ONTWIKKELINGS IN GESONDHEIDSDIENSLEWERING IN DIE REPUBLIEK VAN SUID-AFRIKA GEDURENDE DIE SEWENTIGERJARE
}

\author{
ODELIA H. MULLER
}

\begin{abstract}
SUMMARY
A number of major developments have brought about important changes in the delivery and co-ordination of health services in South Africa.

Some of these developments are:

- the hospital-centric community-directed health services which were developed in the national states:

- the changes to programme-budgeting which highlighted priority areas;

- the Health Act 63 of 1977 which provides for a formal structure for co-ordination of health services and the development of national health policy;

- rationalisation in the civil service by which one Department of Health. Welfare and Pensions was created;

- the Health Services Facilities Plan announced by the Minister of Health in 1980. This plan will greatly enhance the development of comprehensive health services for the South African community. The plan describes six levels according to which health services will be developed: providing for basic health needs; health education: primary health care (including self-care, community responsibility, community nursing and community health centres): the community hospital; the regional hospital; the academic hospital.
\end{abstract}

\section{INLEIDING}

coos in baie ander lande in die wêreld $\checkmark$ is die gesondheidsdienssisteem in die Republiek besig om ongekende veranderinge te ondergaan.

Hierdie veranderings spruit enersyds voort uit invloede wat van buite deur ander sisteme op die gesondheidsdienssisteem uitgeoefen word - die politieke, die sosiaal-ekonomiese en die onderrigsisteme is enkele van die belangrikstes. Andersyds word veranderinge genoodsaak deur behoeftes wat direk met die gesondheidsdienssisteem verband hou. Hierdie behoeftes word geskep, onder meer deur veranderde siektepatrone en vooruitgang op medies-tegnologiese gebied.

\section{DIE SISTEEM VAN GESOND- HEIDSDIENSLEWERING IN DIE R.S.A.}

Tradisioneel word gesondheidsdienste in die Republiek deur drie owerheidsvlakke gelewer, naamlik: Sentrale Regeringsvlak deur die Departement Gesondheid, Welsyn en Pensioene, deur die provinsiale owerhede op die tweede vlak en deur plaaslike besture op die derde vlak.

Enkele kenmerke van die gefragmenteerde sisteem aan die begin van die sewentigerjare is belangrik, naamlik:
- die Departement van Gesondheid was hoofsaaklik verantwoordelik vir die bevordering van gesondheid en voorkoming van oordraagbare en aansteeklike siektes, asook die totale spektrum van psigiatriese dienste. Die lewering van bevorderende en voorkomende dienste deur plaaslike besture is deur die Departement gesubsidieer. Rehabilitasie is nêrens in gesondheidswetgewing genoem nie;

- provinsiale owerhede, soos tans nog bepaal deur Artikel 84 van die Grondwet van die Republiek van Suid-Afrika 30 van 1961, was verantwoordelik vir die hospitaaldienste dus kuratiewe dienste;

- sendinggenootskappe het 'n belangrike bydrae tot gesondheidsdienste gelewer. Sendinghospitale het hoofsaaklik kuratiewe dienste in plattelandse gebiede gelewer;

- die gemeenskap self het 'n bydrae gelewer in die vorm van klinieke wat deur welsynsorganisasies gestig is. Verpleegkundiges in die klinieke het kraamdienste gelewer en geringer ongesteldhede behandel in areas waar ander dienste nie geredelik beskikbaar was nie;

- die distriksgeneesheerstelsel waar privaatpraktisyns op 'n deeltydse basis teen vasgestelde tariewe ook staatspasiënte behandel en mediesgeregtelike werk behartig het. Wat van groot belang is, is die distrikgeneesheer se aandeel in die voorsiening van mediese dienste in afgeleë gebiede;

-- die immunisering teen aansteeklike/oordraagbare siektes wat deur gesondheidsassistente in plattelandse gebiede waargeneem is.

Terwyl gesondheidsdienste tog wel beskikbaar was, was die sisteem oorwegend toegespits op die voorsiening van kuratiewe dienste - ook op die platteland. Koördinering van beleid, beplanning en daarstelling van gesondheidsdienste het egter grootliks ontbreek sodat die sisteem gefragmenteerd ontwikkel het en nie doelbewus voorsiening gemaak het vir die sinvolle ontplooiing van alle fasette van 'n omvattende gesondheidsdiens in plattelandse sowel as stedelike gebiede nie.

\section{BETEKENISVOLLE GEBEURE IN DIE SEWENTIGERJARE}

Alhoewel daar sekerlik talle veranderinge in die Republiek van Suid-Afrika gedurende die afgelope dekade was wat 'n betekenisvolle invloed op die gesondheidsdienssisteem uitoefen, word slegs enkeles hiervan genoem en wel dié wat direk gelei het tot ' $n$ verandering in 
houding met betrekking tot gesondheidsdienslewering, koördinering tussen die verskillende owerhede en tot die formulering van die Nasionale Gesondheidsdiensfasiliteiteplan.

\section{Die nasionale state}

Die implementering van regeringsbeleid vir die staatkundige ontwikkeling van nasionale state het verreikende gevolge vir die gesondheidsdienssisteem gehad.

Onder meer:

- is die sendinghospitale wat in selfregerende gebiede geleë sou wees in die vroeë sewentigerjare genasionaliseer en het dit deel geword van die gesondheidsdienste van die verskillende state;

- is 'n enkelvlak-gesondheidsdienssisteem in die nasionale state ontwikkel. Die sisteem is welbekend naamlik 'n hospitaalsentriese, gemeenskapgerigte sisteem waar satellietklinieke 'n kernrol vervul in die lewering van 'n omvattende gesondheidsdiens en waar gesondheids- en welsynsdienste geïntegreerd gelewer word en in een Departement van Gesondheid en Welsyn verenig is;

- het gemeenskapsbetrokkenheid, inderdaad gemeenskapsontwikkeling, onafskeibaar deel van die gesondheidsdienssisteem geword;

- moes spesifieke strukture ontwikkel word om koördinering van gesondheidsdienste in Suid-Afrika te bewerkstellig.

\section{Die finansiële beheersisteem in die staatsdiens}

Weer eens in die vroeë sewentigerjare was die destydse Departement van Gesondheid een van die eerste staatsdepartemente wat van die tradisionele finansiële beheerstelsel oorgeskakel het na die sogenaamde programbeheerstelsel. Hierdie stelsel het onder meer stukrag verleen aan:

- die bepaling van doelstellings en meetbare mikpunte vir daardie dienste waarvoor die Departement verantwoordelik is;

- die uitbou van 'n sterk epidemiologie-afdeling wat skakeling in die Suider-Afrikakonteks handhaaf;

- die identifisering van leemtes in en toewysing van fondse vir die lewering van primêre gesondheidsdienste, met skoolgesondheidsdienste vir Swart, Kleurling en Indiërkinders sowel as fasette van bejaardesorg inbegrepe;

- die uitbou van die nasionale gesinsbeplanningsprogram;

- die uitbou van 'n netwerk van psigia- triegemeenskapsdienste wat gesonde skakeling handhaaf met ander bevorderende, voorkomende en rehabilitasiedienste in die gemeenskap;

- die ontwikkeling van 'n wetenskaplik gefundeerde program vir die bestryding van onder meer tuberkulose, waarby die deelname van welsynsorganisasies soos SANTA en die gemeenskap in die breë verseker word;

- die lewering van tandheelkundige en laboratoriumdienste op nasionale grondslag.

\section{Die wet op gesondheid 63 van 1977}

Dit is nie die doel van hierdie artikel om die Wet op Gesondheid 63 van 1977 in detail te ontleed of sy bepalinge te bespreek nie. Baie is al hieroor geskryf. Eerder word enkele aspekte weer eens uitgelig ten einde die noodsaaklikheid van koördinering en doelgerigte ont-

\section{FIGUUR 1. 'N SKEMATIESE VOORSTELLING VAN DIE KOÖRDINE- RINGSTRUKTUUR GESKEP DEUR DIE WET OP GESONDHEID 63 VAN 1977}

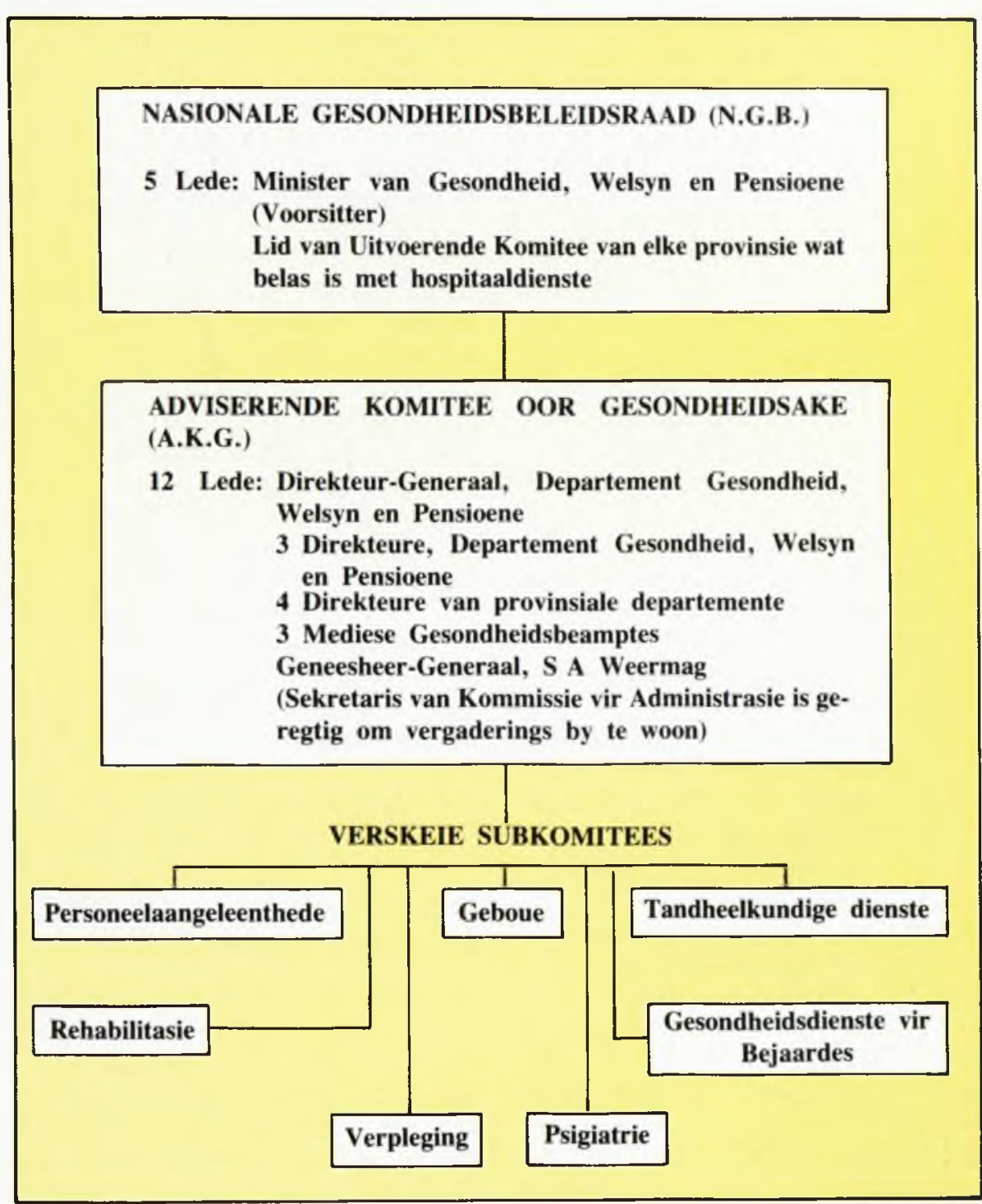

plooiing van 'n omvattende diens te beklemtoon.

\section{Koördineringstrukture wat deur die wet daargestel word}

Die beginsel van koördinasie lê ten grondslag aan die bepalings van die Wet op Gesondheid 63 van 1977. Inderdaad word koördinering in die Wet as taak opgedra aan alle owerhede. (Kyk Artikels $14(1)(\mathrm{c}), 16(\mathrm{~g})$ en $20(1)(\mathrm{d}))$

Hierbenewens word daar 'n formele struktuur deur die bepalings van die Wet geskep, nie net vir die formulering van nasionale beleid oor sekere aangeleenthede nie, maar ook vir die koördinasie van gesondheidsdienste en voorsiening van fasiliteite vir dienslewering, sowel as die opleiding van gesondheidsdienspersoneel (kyk in hierdie verband na Hoofstuk 1 van die Wet). 'n Skematiese voorstelling van die koördineringstruktuur word in Figuur 1 gegee. 
Benewens daardie subkomitees wat ingevolge Artikel 6(1) van die Wet aangestel is, is daar reeds ingevolge Artikel 6(2) verskeie ander subkomitees aangestel waaronder die subkomitee vir Verpleegkunde, die subkomitee vir Gesondheidsdienste vir Bejaardes, subkomitee vir Psigiatriese Dienste en die subkomitee vir Moeder en Kinddienste.

Dit is interessant om, betreffende die subkomitees, op die volgende te let:

- die voorsitter van elke subkomitee is 'n lid van die Adviserende Komitee oor Gesondheidsake;

- die Departement Gesondheid, Welsyn en Pensioene, die vier provinsiale administrasies en plaaslike besture is altyd verteenwoordig, asook die Suid-Afrikaanse Weermag;

- waar moontlik is verteenwoordiging in die subkomitees veelvolkig;

- die gemeenskap word in verskeie subkomitees deur benoemde lede verteenwoordig;

- subkomitees kan koördinerende komitees op provinsiale of streekbasis aanwys om koördinering op daardie vlak te bewerkstellig oor aangeleenthede wat binne die raamwerk van die betrokke subkomitee se doelstellings val;

- benewens die subkomitee vir Verpleegkunde waar alle lede behalwe die voorsitter geregistreerde verpleegkundiges is, dien verpleegkundiges ook in verskeie van die ander subkomitees.

Die vraag word dikwels gevra of daar ten opsigte van gesondheidsaangeleenthede ook met die onafhanklike en selfregerende nasionale state - en ander Bruin state - skakeling en koördinering plaasvind. R.H.O.S.A., die Regional Health Organisation of Southern Africa, is op regeringsvlak in die lewe geroep om in hierdie behoefte te voorsien. Lidmaatskap van hierdie organisasie is vrywillig. Sy hoofkantoor is in Pretoria gesetel. Behalwe die oorhoofse Raad van R.H.O.S.A. is daar twee staande komitees, naamlik 'n komitee vir Epidemiologie en 'n komitee vir Gesondheidsbevordering. Daar is egter ook 'n komitee wat gemoeid is met verpleegaangeleenthede - die Expert Committee on the Nursing Profession - waarin verteenwoordigers van die verskillende lidlande van R.H.O.S.A. dien. Sou 'n nasionale staat verkies om nie 'n lid van R.H.O.S.A. te wees nie, word skakeling onafhanklik van R.H.O.S.A. bewerkstellig en is daar ook op streekvlak koördinering- en pasiëntverwysingsis- teme waar skakeling meer informeel plaasvind.

\section{Primêre gesondheidsdienste in plat- telandse gebiede}

Soos reeds gemeld, is die dienste wat in plattelandse gebiede beskikbaar was voor die sewentigerjare hoofsaaklik kuratief van aard, met 'n sterk sendinghospitaal- en distrikgeneesheerinslag met 'n bykomende immuniseringsdiens wat deur gesondheidsassistente gelewer is. (Kaapland, waar die Afdelingsrade primêre gesondheidsdienste lewer, uitgesluit). Kliniekdienste van welsynsorganisasies het natuurlik ook 'n bydrae gelewer. Die plaaslike landdros het sekere verpligtinge ingevolge die ou gesondheidswetgewing uitgevoer, onder andere is aansteeklike siektes by hom aangemeld. Ingevolge artikel 30 van die Wet op Gesondheid is die DirekteurGeneraal van die Departement Gesondheid, Welsyn en Pensioene die plaaslike bestuur in areas waar daar nie sodanige ander besture is nie.

Hierdie sogenaamde Artikel 30-areas kom slegs in Transvaal, die Oranje-Vrystaat en Natal voor. Die ontwikkeling van primêre gesondheidsdienste sedert die promulgering van die Wet op Gesondheid 63 van 1977 word breedvoerig in ' $n$ ander artikel in hierdie uitgawe bespreek.

\section{Die rasionaliseringsprogram in die staatsdiens}

Rasionalisasie gaan nie slegs om kosteeffektiwiteit en beter benutting van mannekrag nie. Dit gaan ook daarom dat openbare dienste wat bymekaar hoort, saamgevoeg word ten einde beter diens aan die gemeenskap te kan lewer.

Die voormalige Departemente van Gesondheid en van Welsyn en Pensioene het in die loop van 1980 verenig om een Departement Gesondheid, Welsyn en Pensioene daar te stel. Hierdie verwikkelinge hou noodwendig belangrike implikasies in vir die uitskakeling van duplikasie en oorvleueling van dienste veral met betrekking tot gesinsgesondheidsdienste, psigiatrie-dienste en gesondheidsdienste vir bejaardes.

\section{DIE NASIONALE GESOND- HEIDSDIENSFASILITEITE}

Ten grondslag van die formulering van die Nasionale Gesondheidsdiensfasiliteiteplan is die behoefte aan beleid waarvolgens nie net fasiliteite nie, maar ook die lewering van gesondheidsdienste en die voorsiening van fondse vir die ontplooiing van 'n omvattende gesondheidsdiens, stelstelmatig en doelgerig kan geskied.

Verskeie minder belangrike beginsels is in die plan ingeweef naamlik:

- sentralisasie van beleidsformulering en beplanning van dienste, fasiliteite en gesondheidsdiensstrategie;

- desentralisasie van dienste en fasiliteite volgens 'n patroon waarin die bevorderende, voorkomende, kuratiewe en rehabilitasiekomponente elk sy regmatige plek in die omvattende diens inneem, terwyl gesofistikeerde diagnostiese, terapeutiese en rehabilitasie-dienste meer sentraal beskikbaar gestel word;

- klemverskuiwing van in kuratief gerigte diens na 'n diens waarin aandag geskenk word ook aan basiese lewensbehoeftes, gesondheidsbevordering en al die ander fasette van primêre gesondheidsorg;

- erkenning van die noodsaaklikheid van gemeenskapsbetrokkenheid en -ontwikkeling in die gesondheidsdienssisteem;

- koördinering van dienste en inderdaad gesamentlike benutting van fasiliteite deur die verskillende owerhede wat vir gesondheidsdienslewering verantwoordelik is;

- erkenning van die taak van die privaatpraktisyn en inskakeling van sy dienste by dié van die owerheidsektor.

Die rol van koördineringstrukture in die formulering van die nasionale gesondheidsdiensfasiliteiteplan

Die Gesondheidsdiensfasiliteiteplan is geformuleer deur die subkomitee vir Gesondheidsdiensgeboue en aan die Adviserende komitee vir Gesondheidsake voorgelê. Hierdie Komitee het op sy beurt die aangeleentheid aan die $\mathrm{Na}$ sionale Gesondheidsbeleidsraad voorgelê, waar die plan goedgekeur is. Die Minister van Gesondheid. Welsyn en Pensioene het in November 1980 aangekondig dat die Regering die Gesondheidsdiensfasiliteiteplan voortaan as beleid vir die daarstelling van gesondheidsdiensfasiliteite aanvaar. Dit is dus duidelik dat die koördineringsisteem wat deur die Wet op Gesondheid 63 van 1977 daargestel is, ' $n$ rol speel met betrekking tot die formulering van beleid wat nie onderskat moet word nie.

\section{Struktuur van 'n nasionale ge- sondheidsdiensfasiliteiteplan vir die Republiek van Suid-Afrika}

\section{Vlak 1 - Voorsiening in basiese be- hoeftes}

Om 'n heel basiese vlak van minimale 
gesondheid te handhaaf, is daar vier vereistes in volgorde van belangrikheid, naamlik:

— veilige drinkwater;

- voldoende voedsel vir menslike bestaan;

- basiese riool- en afvalverwydering;

- redelike behuising.

Die Departement Gesondheid, Welsyn en Pensioene moet as koördinerende liggaam optree om, in samewerking met die betrokke owerhede, die nodige maatreëls te tref vir die instelling van die minimum standaarde by die genoemde vier basiese behoeftekomponente.

\section{Vlak 2 - Gesondheidsvoorligting}

Op hierdie gebied is daar drie fasette waarna omgesien moet word:

- minimum onderwysvlak: dit is die verantwoordelikheid van die verskillende departemente van onderwys;

- opleiding en opvoeding: dit is die verantwoordelikheid van die gemeenskap en privaatsektor by wyse van gemeenskapsaktiwiteite en die media.

- gesondheidsvoorligting: is hoofsaaklik die verantwoordelikheid van die Departement Gesondheid, Welsyn en Pensioene en plaaslike besture en in ' $n$ mindere mate provinsiale administrasies en die privaatsektor.

\section{Vlak 3 - Primêre gesondheidsorg}

Daar is drie ontwikkelingsfases.

SELFSORG EN GEMEENSKAPS. VERANTWOORDELIKHEID

Die mees elementêre diens word in 'n gemeenskap deur middel van vrywillige gesondheidsdiensorganisasies gelewer. Die uitgangspunt is dat sodanige organisasies aktief as deel van die gemeenskapsaktiwiteite moet ontstaan en ontwikkel.

Dit behels hoofsaaklik voorkomende, bevorderende en rehabiliterende dienste. Gesondheidsowerhede moet doelbewus samewerking met vrywillige diensorganisasies uitbou sodat daardie organisasies ook 'n aktiewe rol kan vervul in die lewering van gesondheidsdienste.

\section{GEMEENSKAPSVERPLEGING}

Die volgende kategorie van diens het 'n voorkomende en kuratiewe inslag en word deur verpleegkundiges in die gemeenskap gelewer. Daar word gebruik gemaak van bestaande en beskikbare akkommodasie wat vir kliniekdienste improviseer word, en tuisbesoeke word ook gedoen.
Die finansiële voorsiening vir so 'n verpleegdiens is afkomstig van:

- die Departement Gesondheid, Welsyn en Pensioene en/of

- die provinsiale administrasies en/of - plaaslike besture.

Die diens behoort hoofsaaklik deur plaaslike besture en provinsiale administrasies gelewer te word, met inagneming van sekere dienste wat hoofsaaklik die verantwoordelikheid van die Departement Gesondheid, Welsyn en Pensioene is, soos psigiatrie, tuberkulosebestryding, gesinsbeplanning, en bejaardesorg.

\section{DIE GEMEENSKAPSGESOND- HEIDSENTRUM (GGS)}

Die grootte van GGS sal van die gemeenskap wat dit moet bedien, afhang. Basiese fasiliteite vir minstens die volgende dienste moet by elke GGS voorsien word:

- voor- en nageboortesorg met gesinsbeplanning;

- immunisering;

- daaglikse behandeling van siek pasiënte;

- bestryding van tuberkulose en oordraagbare siektes;

- veneriese siektes;

- kindersorg;

- kankerondersoeke (by gesinsbeplanning);

- bejaardesorg;

- gesondheidsvoorligting - veral ten opsigte van voeding;

-- afsonderlike lokaal as vergaderplek van vrywillige diensorganisasies.

Die daarstelling van 'n GGS moet 'n gesamentlike onderneming van al die betrokke gesondheidsowerhede wees. Ten einde die dienste van private geneeshere te bekom, moet die gesondheidsowerhede geriewe vir hulle op 'n selektiewe grondslag by sekere GGS beskikbaar stel.

Voorsiening van fondse deur die sentrale regering word slegs gedoen aan die hand van norme wat neergelê is.

\section{Vlakke 4, 5 en 6 - Hospitalisasie}

Die toekomstige behoefte aan en voorsiening van hospitaalbedde sal hoofsaaklik afhang van die voorsiening van gemeenskapsgesondheidsentra

\section{Vlak 4 - Die gemeenskapshospitaal}

By hierdie hospitaal word hoofsaaklik fasiliteite vir algemene praktisynsdienste voorsien terwyl sekere spesialisdienste toevallig ook daar gelewer kan word.

Daar word voorsien dat 'n ekonomiese eenheid nie kleiner as 100 bedde moet wees en nie 350 bedde moet oorskry nie.

\section{Vlak 5 - Die streekhospitaa}

By hierdie hospitale moet daar, benewens die algemene-praktisynsdiens, die basiese spesialisdienste van algemene chirurgie, interne geneeskunde, verloskunde en ginekologie en pediatrie (indien moontlik) beskikbaar wees.

Bedvoorsiening moet ongeveer 500 bedde wees en in uitsonderlike gevalle moet dit tot 'n maksimum van 800 bedde verhoog kan word

Provinsiale administrasies sal self bepaal watter hospitale tot die status van 'n streekhospitaal verhef moet word.

\section{Vlak 6 - Die akademiese hospitaal}

Hierdie hospitaal maak voorsiening vir al die akademiese gesondheidskomponente, dit wil sê algemene-praktisynsdienste en spesialisdienste op 'n uitgebreide en gesofistikeerde grondslag.

Dit is belangrik dat die hospitaal beperk word tot 800 bedde en nie 1200 mag oorskry nie. Op voorwaarde dat gemeenskapsgesondheidsdienste toereikend voorsien word, kan algemene hospitaalbedde op die basis van twee tot vier bedde per duisend van die bevolking volgens gemeenskapsbehoeftes voorsien word.

\section{SLOTOPMERKINGS}

Aanpassing by verandering is geneig om 'n leefwyse te word in so 'n mate dat die doelgerigtheid daarvan vervaag en slegs die onmiddellike probleme van dienslewering en die spanning wat daaruit voortspruit ' $n$ werklikheid is.

Veranderinge in die gesondheidsdienssisteem van die Republiek van Suid-Afrika is doelgerig. Daar word gestreef na die ideaal om die gesondheid van die inwoners van die Republiek te bevorder, sodat iedere persoon in staat gestel word om 'n toestand van volkome fisiese, psigiese en maatskaplike welsyn te bereik en te handhaaf. (Wet op Gesondheid 63 van 1977, Artikel 10).

Daar sal noodwendig terugslae wees en probleme ondervind word om hierdie ideaal te bereik. Wanneer daar egter gelet word op die vordering wat in een dekade gemaak is om verandering teweeg te bring, dan is daar voldoende rede vir optimisme oor die toekoms.

\section{BIBLIOGRAFIE}

\footnotetext{
1. Departement van Gesondheid, Welsyn en Pensioene. Jaarverslag 1980

Wet op Gesondheid 63 van 1977 